\title{
sciendo
}

\section{ACCURACY OF GENOMIC-POLYGENIC AND POLYGENIC BREEDING VALUES FOR AGE AT FIRST CALVING AND MILK YIELD IN THAI MULTIBREED DAIRY CATTLE*}

\author{
Tawirat Konkruea ${ }^{1}$, Skorn Koonawootrittriron ${ }^{1 \bullet}$, Mauricio A. Elzo ${ }^{2}$, Thanathip Suwanasopee \\ ${ }^{1}$ Department of Animal Sciences, Faculty of Agriculture, Kasetsart University, \\ Chatuchak, Bangkok 10900, Thailand \\ ${ }^{2}$ Department of Animal Sciences, University of Florida, Gainesville, 32611 FL, USA \\ •Corresponding author: agrskk@ku.ac.th
}

\begin{abstract}
Single-nucleotide polymorphisms (SNPs) have been used in genomic prediction and shown to increase prediction accuracy and selection responses for economic traits in dairy cattle. The successful report in genomic prediction for improving age at first calving (AFC) and 305-d milk yield (MY) in multibreed dairy population is limited. Therefore, the objective of this research was to compare estimates of variance components, genetic parameters, and prediction accuracies for AFC and MY using a genomic-polygenic model (GPM) and a polygenic model (PM). The AFC and MY records of 9,106 first-lactating multibreed dairy cows, calved between 1991 and 2014, were collected from 1,012 Thai dairy farms. The SNP genotyped individuals were selected from cows that had completed pedigree and phenotypes information. The total genomic DNA samples of 2,661 dairy cattle were genotyped using various GeneSeek Genomic Profiler low-density bead chips $(9 \mathrm{~K}, 20 \mathrm{~K}$, and $80 \mathrm{~K})$. The 2-trait GPM and PM contained herd-year-season and heterosis as fixed effects, and animal additive genetic and residual as random effects. Variance components and genetic parameters were estimated using the procedure of average information-restricted maximum likelihood (AI-REML). Estimates of additive genetic variance components and heritabilities from GPM were higher than PM for AFC and MY. Correlations between AFC and MY were near zero for both models. Mean EBV accuracies were higher for GPM (32.95\% for AFC and 38.24\% for MY) than for PM (32.65\% for AFC, and 32.99\% for MY). Mean sire EBV accuracies were higher for GPM (31.35\% for AFC and 36.25\% for MY) than for PM (28.37\% for AFC and $28.80 \%$ for MY). Thus, the GPM should be considered the model of choice to increase accuracy of genetic predictions for AFC and MY in the Thai multibreed dairy population.
\end{abstract}

Key words: accuracy, age at first calving, dairy cattle, milk yield, genomic EBV

*Source of research financing: 1) Research co-funds from the National Science and Technology Development Agency (NSTDA), Kasetsart University, and the Dairy Farming Promotion Organization; project no. P-11-00116, and 2) Kasetsart University (project no. SK[KS]1.58). 
Identification of superior animals for economically important traits with high accuracy is an important factor for successful dairy breeding programs. Best linear unbiased prediction (BLUP) is a powerful method to predict breeding values of individual animals which has been widely applied for genetic selection in dairy breeding programs of many countries. This method originally utilized only pedigree and phenotypic records; hence, prediction accuracy depended on numbers of records and additive relationships among animals in the population. However, the development of dense single nucleotide polymorphism (SNP) chips allowed the utilization of SNP genotypes for genetic prediction (Meuwissen et al., 2001). Combining genomic SNP information with pedigree and phenotypic information to compute genetic predictions using BLUP showed that it would help increase the accuracy of genetic prediction and selection, and reduce the cost of genetic improvement programs as the cost of genotyping these genomic SNP has been dramatically reduced (Schenkel et al., 2009; VanRaden et al., 2009; De Roos et al., 2011; Wiggans et al., 2011) and genomic selection could potentially lead to a doubling of the rate of genetic gain through selection and breeding from bulls at two years of age rather than at five years of age or later, which could save up to $92 \%$ of their cost (Schaeffer, 2006).

Age at first calving (AFC) and 305-d milk yield (MY) are economically important traits for the dairy cattle business. Thai dairy farmers prefer cows with low AFC and high MY (Koonawootrittriron et al., 2006; Konkruea et al., 2017). Reliable identification and selection of superior animals for AFC and MY require highly accurate genetic predictions. However, numbers of available phenotypes and pedigree records in Thailand are small and additional yearly phenotype and pedigree records are limited (Dairy Farming Promotion Organization, 2017). Multiple genomic selection studies have indicated that the size of the reference population needs to be very large to predict genomic EBV with high accuracy and that predictions obtained with a reference population of one breed do not appropriately predict the genomic EBV of these animals in other breeds (Harris et al., 2008; Hayes et al., 2009 a; VanRaden et al., 2009). Thus, a multibreed reference population is appropriate to obtain genomic EBV in dairy cattle populations composed of various breeds and crossbred groups, particularly when some of the breeds have limited numbers of genotypes and phenotypes (Hayes et al., 2009 b; Erbe et al., 2012). Further, utilization of a genomic-polygenic model that combines information from phenotypes, pedigree, and SNP genotypes would be expected to yield higher prediction accuracies for AFC and MY than those from a polygenic model that only uses phenotypes and pedigree in the Thai multibreed dairy population. Thus, the objective of this study was to compare the estimates of variance components, genetic parameters, and prediction accuracies for AFC and MY between a genomic-polygenic model (GPM) and a polygenic model (PM) in the Thai multibreed dairy population.

\section{Material and methods}

\section{Data, traits and animals}

The phenotypes of AFC and MY were gathered from 9,106 first-lactation cows which were raised by 1,012 dairy farms and calved between 1991 to 2015 . The pedi- 
gree file contained 17,516 animals (1,331 sires and 16,185 dams). Holstein purebred and crossbred sires and dams were represented as parents in the multibreed population (Koonawootrittriron et al., 2009). The Thai multibreed population was generated by upgrading various breeds to Holstein. Thus, cows could have up to seven breeds (Brahman, Brown Swiss, Jersey, Red Dane, Sahiwal, Red Sindhi and Thai Native) represented in their genome. However, most animals were over 75\% Holstein (mean $=85.97 \%$ Holstein; SD $=14.39 \%$ Holstein). There were 1,057 Holstein purebred and 274 crossbred Holstein-Other Breeds sires mated to 536 Holstein purebred and 15,649 crossbred Holstein-Other Breeds cows.

The mean (standard deviation) was 30.9 mo (5.6 mo) for AFC, and 4,307 kg $(1,083 \mathrm{~kg})$ for MY. The range was from 17 to $50 \mathrm{mo}$ for AFC, and from 1,500 kg and $8,896 \mathrm{~kg}$ for MY. Means and standard deviations of AFC and MY in this population were similar to those corresponding values from the previous studies in Thailand. The mean (standard deviation) $31.0 \mathrm{mo}(6.2 \mathrm{mo})$ for AFC, and 4,311 kg (1,079 kg) for MY were reported by the Dairy Farming Promotion Organization of Thailand (DPO, 2017), and $31.0 \mathrm{mo}(5.8 \mathrm{mo})$ for AFC, and 4,212 kg (1,066 kg) for MY were reported by the Department of Livestock Development (DLD, 2017).

Blood samples were collected from 2,572 cows and semen samples were collected from 89 sires. All animals had complete pedigree and phenotypic information. Genomic DNA was extracted from individual blood sample using the protocol from MasterPure $^{\mathrm{TM}}$ DNA Purification Kit (Epicenter ${ }^{\circledR}$, Madison, WI, USA). The Genomic DNA from frozen semen was extracted using GenElute ${ }^{\mathrm{TM}}$ Mammalian Genomic DNA Miniprep Kit (Sigma ${ }^{\circledR}$, Ronkonkoma, NY, USA). Measurement of DNA quality and quantity was done using NanoDrop ${ }^{\mathrm{TM}} 2000$ Spectrophotometer (Thermo Fisher Scientific Inc., Wilmington, DE, USA). DNA samples with an A260/A280 ratio of greater than or equal to 1.8 and a concentration of $1.5 \mathrm{ng} / \mu \mathrm{l}$ were accepted for SNP genotyping. The DNA samples were genotyped using Genomic Profiler (GGP) BeadChip platform with various numbers of SNP probes (GeneSeek, Lincoln, NE, USA). The SNP genotyping was done for GGP9K $(n=1,412)$, GGP20K $(\mathrm{n}=570)$, GGP26K $(\mathrm{n}=540)$ and GGP80K $(\mathrm{n}=139)$ chips. Genotype imputation was performed from GGP9K, GGP20K, and GGP26K to GGP80K using FImpute (Sargolzaei et al., 2014) and the following steps of Jattawa et al. (2015). Only SNP markers with minor allele frequencies higher than 0.4 or call rates higher than 0.9 were kept. After quality checks, the final genotypic information, actual SNP and imputed SNP marker, contained 74,144 markers.

\section{Climate, feeding and management}

Thailand is a tropical country located in Southeast Asia with high temperatures (average temperature $27^{\circ} \mathrm{C}$ ), high relative humidity (average relative humidity $75 \%$ ), and yearly Southwest and Northwest monsoons (Thai Meteorological Department, 2010). The months of November to February were defined as Winter (average temperature of $26^{\circ} \mathrm{C}$ and average relative humidity of $69 \%$ ), March to June was Summer (average temperature of $29^{\circ} \mathrm{C}$ and average relative humidity of $72 \%$ ), and July to October was the Rainy season (average temperature of $28^{\circ} \mathrm{C}$ and average relative humidity of $80 \%$ ). Most dairy farms in Thailand are small (less than 10 milking 
cows) and generally have limited land area and insufficient resources to provide high quality feeding and management conditions at critical times (Rhone et al., 2008; Yaemkong et al., 2010; Gebreyohannes et al., 2013).

Cows were kept in open barns and fed roughages and concentrates. Roughages were provided by direct grazing or by cut and carry of fresh grass from artificial or natural grasslands (Penisetum purpurium, Brachiaria mutica, and Penicum maximum). Cows were given approximately $1 \mathrm{~kg}$ of concentrate (14 to 22\% CP, 63 to $83 \%$ NFE) per $2 \mathrm{~kg}$ of milk during milking times, twice a day (5 am and $3 \mathrm{pm}$ ). A mineral supplement was always available. Crop residues (rice straw, sugarcane, and corn stover) or agricultural byproducts (bagasse and cassava pulp) were fed when fresh grass was limited. Cows were bred using artificial insemination all year round. Sires were chosen based on genetic ability for high MY and young AFC among those available at the time of insemination (Konkruea et al., 2017). Primary reasons for culling of cows were reproduction and general health problems (Koonawootrittriron et al., 2009).

\section{Variance components and genetic parameters}

An average information restricted maximum likelihood algorithm was used to estimate variance and covariance components with program AIREMLF90 (Tsuruta, 2014) from the BLUPF90 Family Programs (Misztal et al., 2002). Variance and covariance components were estimated using a 2-trait polygenic model (PM) and a 2-trait genomic-polygenic model (GPM). Fixed effects were contemporary group (herd-yearseason) and heterosis as a function of heterozygosity (probability of having alleles of different breeds in 1 locus over all loci). Random effects were animal additive genetic and residual. The variance-covariance matrix among animal additive genetic effects for the PM was equal to $A \otimes V_{a}$, where $A$ was the additive relationship matrix among all animals, $\mathrm{Va}$ was a $2 \times 2$ matrix of additive genetic variances and covariances between $\mathrm{AFC}$ and MY, and $\otimes$ was the Kronecker product. The variance-covariance matrix among animal additive genetic effects for GPM was equal to, where $\mathrm{H \otimes Va}$ was equal to (Legarra et al., 2009):

$$
H=\left[\begin{array}{cc}
A_{11}+A_{12} A_{22}^{-1}\left(G_{22}-A_{22}\right) A_{22}^{-1} A_{21} & A_{12} A_{22}^{-1} G_{22} \\
G_{22} A_{22}^{-1} A_{21} & G_{22}
\end{array}\right]
$$

where:

$A_{11}$ was the additive relationship submatrix among non-genotyped animals,

$A_{12}$ was the additive relationship submatrix among non-genotyped and genotyped animals,

$A_{22}^{-1}$ was the inverse of the additive relationship submatrix for genotyped animals,

$G_{22}$ was the matrix of genomic relationships among genotyped animals (VanRaden, 2008; Aguilar et al., 2010).

Matrix $\mathrm{H}$ was constructed using the default weight values specified for the BLUPF90 Family of Programs, i.e., tau $=1$, alpha $=0.95$, beta $=0.05$, gamma $=0$, delta $=0$, and omega $=1$. Similarly, matrix $G_{22}$ was scaled using the default restriction that requires the mean of the diagonal elements of $G_{22}$ to be equal to the mean 
of diagonal elements of $A_{22}$, and the mean of the off-diagonal elements of $G_{22}$ to be equal to the mean of off-diagonal elements of $A_{22}$. Standard errors of estimates of additive genetic and residual variances and covariances were computed as square roots of their error variances. Estimates of variance and covariance components were used to estimate heritabilities for, and genetic and phenotypic correlations between AFC and MY. Standard deviations of estimates of heritabilities and correlations were computed using a repeated sampling procedure (Meyer and Houle, 2013) built in program AIREMLF90.

\section{Prediction accuracies}

The estimated breeding values (EBV) for AFC and MY were computed using PM and GPM. Prediction accuracies for EBV were calculated as:

$$
\sqrt{1-\left(\frac{P E V_{i j}}{\sigma_{a i j}^{2}}\right)} \times 100
$$

where:

$P E V_{i j}$ was the prediction error variance,

$\sigma_{\text {aij }}^{2}$ was the additive genetic variance computed with model $\mathrm{i}$,

$i=\mathrm{PM}$ or GPM for trait $\mathrm{j}$,

$j=\mathrm{AFC}$ or $\mathrm{MY}$.

Subsequently, EBV accuracies from PM and GPM were compared for sires, dams, and all animals.

EBV accuracies for AFC and MY were divided into three groups: $\mathrm{H}=$ high accuracy group (over 70\% accuracy), $\mathrm{M}=$ medium accuracy group (50 to $70 \%$ accuracy), and $\mathrm{L}=$ low accuracy group (lower than $50 \%$ accuracy).

The changes in mean EBV accuracies from PM to GPM were classified into nine groups: 1) $\mathrm{HH}=$ group of animals with high mean PM EBV accuracy and high mean GPM EBV accuracy; 2) HM = group of animals with high mean PM EBV accuracy and medium mean GPM EBV accuracy; 3) HL = group of animals with high mean PM EBV accuracy and low mean GPM EBV accuracy; 4) $\mathrm{MH}=$ group of animals with medium mean PM EBV accuracy and high mean GPM EBV accuracy; 5) MM = group of animals with medium mean PM EBV accuracy and medium mean GPM EBV accuracy; 6) $\mathrm{ML}=$ group of animals with medium mean PM EBV accuracy and low mean GPM EBV accuracy; 7) LH = group of animals with low mean PM EBV accuracy and high mean GPM EBV accuracy; 8) LM = group of animals with low mean PM EBV accuracy and medium mean GPM EBV accuracy; and 9) LL = group of animals with low mean PM EBV accuracy and low mean GPM EBV accuracy. These changes in mean EBV accuracy were used to identify groups of animals that increased their EBV accuracies from PM to GPM. 


\section{Results}

\section{Variance components and genetic parameters}

Estimates of variances and covariances for AFC and MY from PM and GPM are shown in Table 1. Although the PM and GPM estimates of the additive genetic variance for AFC were comparable, the GPM estimate of the additive genetic variance for MY was substantially larger than the corresponding PM estimate. The additive genetic covariances were small for both models (negative for GPM and positive for PM). Estimates of GPM environmental variances and covariances were somewhat smaller than PM estimates, but estimates of phenotypic variances and covariances were similar between models.

Table 1. Variance and covariance components for age at first calving (AFC) and milk yield (MY) estimated using a polygenic model (PM) and a genomic-polygenic model (GPM)

\begin{tabular}{|c|c|c|c|c|}
\hline \multirow{2}{*}{ Variance components } & \multicolumn{4}{|c|}{ Model } \\
\hline & PM & SE & GPM & SE \\
\hline \multicolumn{5}{|l|}{ Additive genetic } \\
\hline variance $(\mathrm{AFC}), \mathrm{d}^{2}$ & 2.86 & 0.71 & 3.06 & 0.79 \\
\hline Covariance (AFC, MY), d*kg & -19.18 & 91.95 & 6.36 & 106.24 \\
\hline Variance (MY), $\mathrm{kg}^{2}$ & 101,350 & 23,863 & 161,020 & 28,178 \\
\hline \multicolumn{5}{|l|}{ Environmental } \\
\hline variance (AFC), $d^{2}$ & 16.19 & 0.70 & 16.04 & 0.76 \\
\hline Covariance (AFC, MY), d*kg & 216.82 & 90.62 & 195.60 & 100.01 \\
\hline Variance (MY), $\mathrm{kg}^{2}$ & 545,010 & 23,388 & 490,820 & 25,829 \\
\hline \multicolumn{5}{|l|}{ Phenotypic } \\
\hline variance $(\mathrm{AFC}), \mathrm{d}^{2}$ & 19.05 & 0.40 & 19.11 & 0.40 \\
\hline Covariance (AFC, MY), d*kg & 197.64 & 53.20 & 200.62 & 54.07 \\
\hline Variance (MY), $\mathrm{kg}^{2}$ & 646,360 & 13,436 & 651,590 & 13,800 \\
\hline
\end{tabular}

Heritabilities from GPM were higher $(\mathrm{AFC}=0.16$; $\mathrm{MY}=0.25)$ than those from $\mathrm{PM}(\mathrm{AFC}=0.15 ; \mathrm{MY}=0.16)$. Conversely, genetic, environmental, and phenotypic correlations between AFC and MY were close to zero for both GPM and PM (Table 2).

Table 2. Heritabilities and correlations for age at first calving (AFC) and milk yield (MY) estimated with a polygenic model (PM) and a genomic-polygenic model (GPM)

\begin{tabular}{l|c|c|c|c}
\hline \multirow{2}{*}{\multicolumn{1}{c}{ Parameter }} & \multicolumn{4}{c}{ Model } \\
\cline { 2 - 5 } & PM & SD & GPM & SD \\
\hline Heritability (AFC) & 0.15 & 0.04 & 0.16 & 0.04 \\
Heritability (MY) & 0.16 & 0.04 & 0.25 & 0.04 \\
Genetic correlation (AFC, MY) & -0.04 & 0.18 & 0.01 & 0.16 \\
Environmental correlation (AFC, MY) & 0.07 & 0.03 & 0.07 & 0.04 \\
Phenotypic correlation (AFC, MY) & 0.06 & 0.02 & 0.06 & 0.02 \\
\hline
\end{tabular}




\section{Accuracy of polygenic and genomic-polygenic EBV}

Figure 1 shows the mean EBV accuracies for AFC and MY computed with PM and GPM. Mean EBV accuracies were higher for GPM (32.95\% for AFC and $38.24 \%$ for MY) than for PM (32.65\% for AFC, and 32.99\% for MY). Gains in EBV accuracy between PM and GPM were $0.31 \%$ for AFC and $5.25 \%$ for MY.

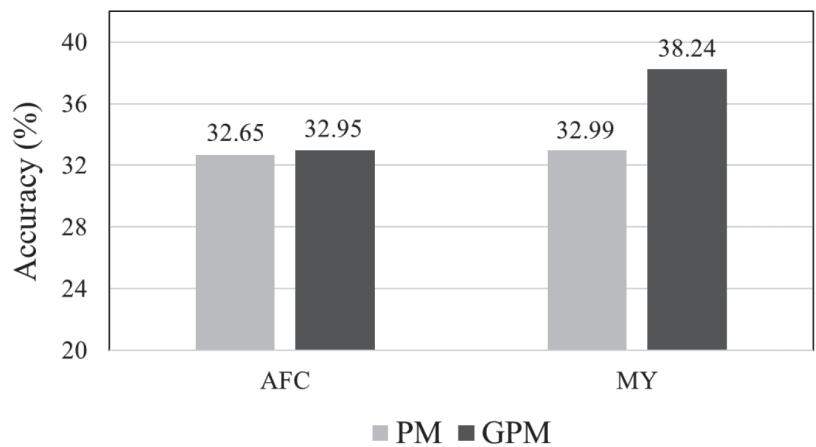

Figure 1. Accuracy of estimated breeding values for age at first calving (AFC) and milk yield (MY) using a polygenic model (PM) and a genomic-polygenic model (GPM)

Figure 2 shows changes in EBV accuracy for age at first calving (AFC) and milk yield (MY) from PM to GPM. The GPM tended to improve the EBV accuracies of animals primarily in the low PM group (lower than 50\% accuracy) and the medium PM group (50 to 70\% accuracy). Animals in the PM high EBV accuracy group (over 70\%) tended to be in the GPM high EBV accuracy group (HH group) for both traits. Although some EBV accuracies from PM groups were similar to those of GPM groups, there were small increases in EBV accuracies from PM to GPM. The trends for AFC EBV accuracies within groups showed small increases in the LL group (from $30.29 \%$ for PM to $30.64 \%$ for GPM) and in the MM group (from $53.72 \%$ for PM to $53.90 \%$ for GPM). Similarly, the trends for MY EBV accuracies showed small increases in the LL group (from $27.00 \%$ for PM to $31.57 \%$ for GPM) and in the MM group (from $52.99 \%$ for PM to $57.53 \%$ for GPM).

Some animals in the PM low and medium EBV accuracy groups tended to move up to the GPM high EBV accuracy group ( $\mathrm{LH}$ and $\mathrm{MH}$ group) for both traits. The trends for AFC showed large increases in the LH group (from 43.46\% for PM to $73.00 \%$ for GPM) and in the MH group (from $60.26 \%$ for PM to $75.75 \%$ for GPM). Similarly, the trends for MY showed large increases in the LH group (from $44.25 \%$ for PM to $74.93 \%$ for GPM) and the MH group (from $61.29 \%$ for PM to $76.47 \%$ for GPM).

There were no animals in PM high EBV accuracy that fell into the GPM low EBV accuracy group (HL group) for both traits. However, there were some animals in the PM high and medium EBV accuracy groups that were in the GPM low EBV accuracy group (HM and ML groups) for both traits. EBV accuracies for AFC decreased from $74.30 \%$ for PM to $65.11 \%$ for GPM in the HM group and from $52.41 \%$ for PM to $46.05 \%$ for GPM in the ML group. Similarly, EBV accuracies for MY de- 
creased from $73.42 \%$ for PM to $66.97 \%$ for GPM in the HM group and from $51.34 \%$ for PM to $46.79 \%$ for GPM the ML group.
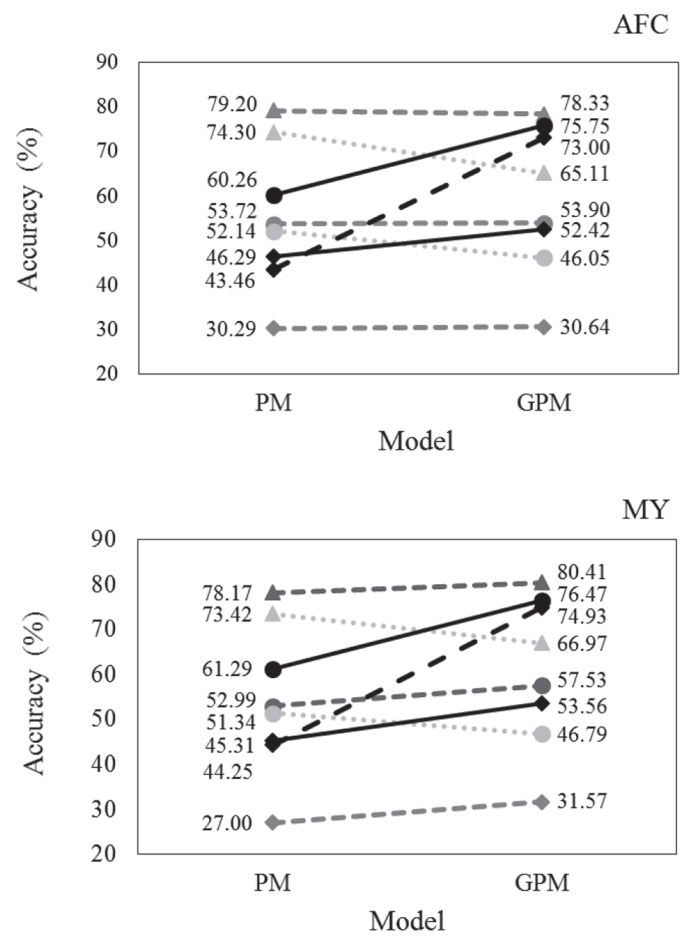

$$
\begin{aligned}
& \text { - 슬- } \mathrm{HH} \text { (21) } \\
& \text { ……HM (15) } \\
& \text { HL (0) } \\
& \longrightarrow \mathrm{MH}(30) \\
& \text { - - MM (576) } \\
& \text {... ML (495) } \\
& \text { ——LH (9) } \\
& \sim \text { LM (368) } \\
& \text { - - LL (12433) }
\end{aligned}
$$

MY

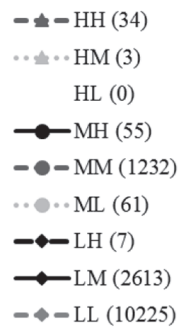

*Numbers in brackets are numbers of animals in each group.

Figure 2. Changes in mean EBV accuracies from a polygenic model (PM) to a genomic-polygenic model (GPM) for (A) Age at first calving (AFC) and (B) Milk yield (MY)

The numbers of animals with EBV accuracies of $70 \%$ and higher was larger with GPM than with PM (Figure 3). There were 24 more animals for AFC and 59 more animals for MY with an accuracy of $70 \%$ or higher with GPM than with PM.

Accuracy $70 \%$

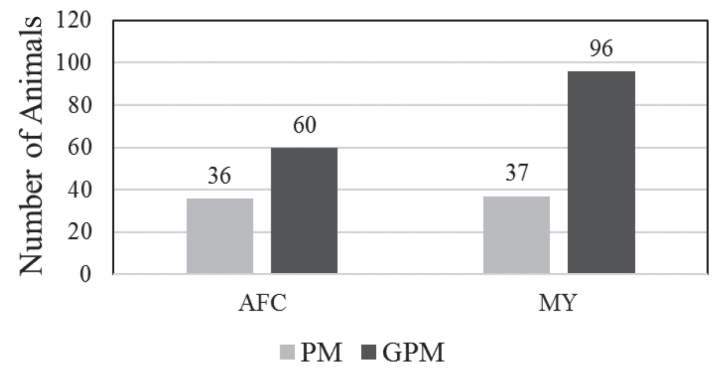

Figure 3. Number of animals with EBV accuracies of $70 \%$ and higher for age at first calving (AFC) and milk yield (MY) using a polygenic model (PM) and a genomic-polygenic model (GPM) 
Figure 4 shows EBV accuracies for AFC and MY computed with PM and GPM for sires and cows. Mean EBV accuracies for sires were higher for GPM $(31.35 \%$ for AFC and $36.25 \%$ for MY) than for PM (28.37\% for AFC and $28.80 \%$ for MY). For cows, the mean EBV accuracies for MY computed with GPM (38.41\%) were higher than the PM (33.35\%), while the mean EBV accuracies for AFC computed with GPM (33.09\%) were close to the PM (33.02\%).

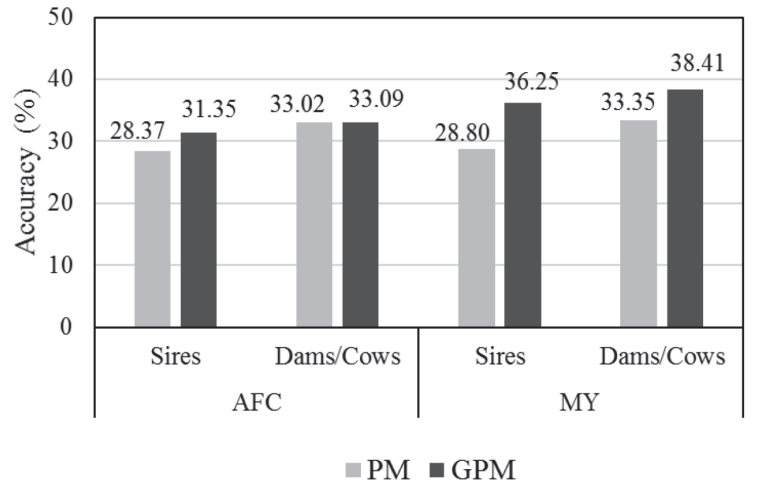

Figure 4. Sire and cow EBV accuracies for age at first calving (AFC) and milk yield (MY) with a polygenic model (PM) and a genomic-polygenic model (GPM)

\section{Discussion}

\section{Variance components and genetic parameters}

The higher estimates of additive genetic variances and heritabilities for AFC and MY from GPM than PM indicated that the combined use of genotypes, pedigree, and phenotypes explained higher fractions of additive genetic variances for these traits than with only pedigree and phenotypes (Elzo et al., 2017). A more precise accountability of additive genetic relationships by GPM than PM may have been partly responsible for these additive genetic variances and heritabilities (Jattawa et al., 2015).

Heritability estimates for AFC with both models were similar to previous PM estimates in the Thai multibreed population ( 0.16 for AFC; Koonawootrittriron et al., 2006). Conversely, although the heritability for MY from PM was lower than previous estimates, the estimate from GPM was comparable to estimates from previous studies using smaller datasets analyzed with either single-trait or multiple-trait models $(0.31 \pm 0.06$ to $0.38 \pm 0.10$ for MY: Koonawootrittriron et al., 2009; Sarakul et al., 2011; Jattawa et al., 2012). Thus, genetic improvement for AFC would likely be slower than for MY in this population because AFC is more influenced by environmental conditions. Improved nutrition, management, and health conditions would help cows to more fully express their genetic potential for both traits. In addition, a higher degree of accuracy of phenotypic and pedigree data collection and 
larger numbers of animals in future years would increase both the size and precision of the genetic evaluation database. These approaches would be expected to increase the accuracy of genetic predictions, improve the identification of superior animals, and increase heritabilities and genetic progress for these traits.

The GPM estimate of heritability for MY (0.25) was within the range of estimates of genomic heritabilities for Holstein cattle from temperate regions $(0.23$ to 0.30; Gao et al., 2012; Rodríguez-Ramilo et al., 2014; Bauer et al., 2015). Higher estimates of heritability for AFC and MY with GPM will increase the accuracy of genetic predictions resulting in a more reliable identification of the superior sires and cows in the Thai dairy population. Consequently, higher rates of genetic change for AFC and MY would be expected with GPM than with PM in this population.

\section{Accuracy of polygenic and genomic-polygenic EBV}

Although overall prediction accuracies for AFC and MY were higher for GPM than for PM, there were some animals whose GPM accuracies for these traits were lower than their PM accuracies. This may have occurred because a sizeable number of SNP from GGP80K inaccurately predicted the value of QTL affecting AFC and MY in these animals resulting in GPM EBV of lower accuracy than their corresponding PM EBV. Conversely, animals where SNP from GGP80K accurately predicted QTL affecting AFC and MY had higher accuracies of GPM EBV than PM EBV. While, the animals whose GPM accuracies for AFC and MY were quite higher than their PM accuracies in HH, MH, and LH groups, those are all sires. The gains of accuracy were substantially high because most sires had high number of progeny and other relatives in the population.

The higher EBV accuracies from GPM than PM agreed with reports that genomic evaluations had higher prediction accuracies for MY than polygenic evaluations in dairy cattle (VanRaden et al., 2009; Mulder et al., 2012). However, the Thai multibreed population had lower gains in accuracy than those reported for Holstein in temperate countries (23\% to 32\%; De Roos et al., 2009; Schenkel et al., 2009; VanRaden et al., 2009; Wiggans et al., 2011). A larger number of genotyped animals in a population would yield higher prediction accuracies (Goddard, 2009; VanRaden et al., 2011; Mulder et al., 2012). Thus, the lower gain in EBV accuracy in this study may have been due to the small number of animals with genotypes (2,661 animals) compared to other studies with Holstein populations (5,335 to 63,615 animals). Accordingly, the accuracy of genomic evaluations in Thailand would be expected to increase as more dairy cattle are genotyped in future years.

The higher increase in EBV accuracy from PM to GPM for MY than for AFC may have been due to a closer association between genotypes in the GeneSeek chips used here with MY than with AFC. Several studies have obtained higher prediction accuracies for MY than for other traits when using genomic information (Moser et al., 2010; Erbe et al., 2012; Karoui et al., 2012; Jattawa et al., 2015). This may be partly due to the effect of the heritability on the accuracy of genomic predictions (Goddard, 2009; Hayes et al., 2009 a). Traits with higher heritability will yield EBV of higher accuracy (Moser et al., 2010; Bohlouli et al., 2017). Thus, the higher increase in EBV accuracy for MY than for AFC was a consequence of the medium 
GPM heritability estimated for MY and the low GPM heritability estimated for AFC in this population.

The higher EBV accuracies obtained with GPM indicated that genomic information was successful at increasing prediction accuracies in this population beyond the levels achieved with PM. This result agreed with results in other dairy populations (Van Doormaal et al., 2009; Wiggans et al., 2011; Su et al., 2012; Thomasen et al., 2012; Bauer et al., 2014; Přibyl et al., 2014; Bauer et al., 2015; Jattawa et al., 2015) that reported utilization of genomic information in addition to pedigree and phenotypic information generating higher prediction accuracies in dairy populations.

\section{Acknowledgements}

The authors thank the National Science and Technology Development Agency (NSTDA), Kasetsart University, the Dairy Farming Promotion Organization for funding support (Research Project no. P-11-00116 under the Industry Research Collaboration; NUI-RC), and for awarding a scholarship to the first author. Sincere thanks are expressed to Kasetsart University (Increasing genetic potential of Thai cattle using genomic selection, SK[KS]1.58) and the University of Florida (Gainesville, Florida, USA) for all the support provided to this research.

\section{References}

Aguilar I., M is z t a 1 I., J ohn son D.L., Le garra A., Tsurut a S., L a w 1 or T.J. (2010). Hot topic: a unified approach to utilize phenotypic, full pedigree, and genomic information for genetic evaluation of Holstein final score. J. Dairy Sci., 93: 743-752.

B a u e J J., Vostrý L., Přibyl J., Svitáková A., Zavadilová L. (2014). Approximation of reliability of single-step genomic breeding values for dairy cattle in the Czech Republic. Anim. Sci. Pap. Rep., 32: 301-306.

B a u e r J., Přibyl J., Vostrý L. (2015). Short communication: reliability of single-step genomic BLUP breeding values by multi-trait test-day model analysis. J. Dairy Sci., 98: 4999-5003.

B ohlouli M., Alijani S., Javaremi A.N., König S., Yin T. (2017). Genomic prediction by considering genotype $\times$ environment interaction using different genomic architectures. Ann. Anim. Sci., 17: 683-701.

Dairy Farming Promotion Organization (2017). DPO sire and dam summary 2017. Ministry of Agriculture and Cooperation, Bangkok, Thailand. pp. 1-106.

De Roos A.P.W., Schrooten C., Mullaart E., Van Der Beek S., De Jong G., Vos $\mathrm{k}$ a $\mathrm{m}$ p W. (2009). Genomic selection at CRV. Proc. Interbull Technical Workshop - genomic information in genetic evaluation, Uppsala, Sweden. pp. 47-50.

De Roos A.P.W., S chrooten C., Veerkamp R.F., Van Arendonk J.A.M. (2011). Effects of genomic selection on genetic improvement, inbreeding, and merit of young versus proven bulls. J. Dairy Sci., 94: 1559-1567.

Department of Livestock Development (2017). DLD dairy sire summary 2017. Bureau of Biotechnology in Livestock Production Department of Livestock Development, Bangkok, Thailand. pp. 1-87.

El zo M.A., Mate e s cu R.G., Johns on D.D., S cheffler T.L., S cheffler J.M., Carr C., R a e D.O., Was din J.G., Driver M.D., D river J.D. (2017). Genomic-polygenic and polygenic predictions for nine ultrasound and carcass traits in Angus-Brahman multibreed cattle using three sets of genotypes. Livest. Sci., 202: 58-66.

Erbe M., Hayes B.J., Matukumalli L.K., Goswami S., Bowman P.J., Reich C.M., M a s o n B.A., Go d d a rd M.E. (2012). Improving accuracy of genomic predictions within and 
between dairy cattle breeds with imputed high-density single nucleotide polymorphism panels. J. Dairy Sci., 95: 4114-4129.

Gao H., Christensen O.F., Madsen P., Nielsen U.S., Zhang Y., Lund M.S., Su G. (2012). Comparison on genomic predictions using three GBLUP methods and two single-step blending methods in the Nordic Holstein population. Genet. Sel. Evol., 44: 1-8.

Gebreyohannes G., Koonawootrittriron S., Elzo M.A., Suw anasopee T. (2013). Variance components and genetic parameters for milk production and lactation pattern in an Ethiopian multibreed dairy cattle population. Asian-Aust. J. Anim. Sci., 26: 1237-1246.

G o d d a r d M. (2009). Genomic selection: prediction of accuracy and maximization of long term response. Genetica, 136: 245-257.

Harris B.L., J ohns on D.L., S pelman R.J. (2008). Genomic selection in New Zealand and the implications for national genetic evaluation. Proc. Interbull Meeting, Niagara Falls, Canada.

Ha ye s B.J., B ow man P.J., Chamberla in A.C., Goddard M.E. (2009 a). Invited review: Genomic selection in dairy cattle: Progress and challenges. J. Dairy Sci., 92: 433-443.

H a y e s B.J., B ow man P.J., Cha m b e r la in A.C., Verbyla K., Go d d a rd M.E. (2009 b). Accuracy of genomic breeding values in multi-breed dairy cattle populations. Genet. Sel. Evol., 41: 51.

Jattawa D., Koonawootrittriron S., Elzo M.A., Suwanasopee T. (2012). Somatic cells count and its genetic association with milk yield in dairy cattle raised under Thai tropical environmental conditions. Asian-Aust. J. Anim. Sci., 25: 1216-1222.

Jattawa D., Elzo M.A., Koonaw ootrittriron S., Suw an as opee T. (2015). Comparison of genetic evaluations for milk yield and fat yield using a polygenic model and three genomic-polygenic models with different sets of SNP genotypes in Thai multibreed dairy cattle. Livest. Sci., 181: 58-64.

Karoui S., Carabaño M.J., Día z C., L e garra A. (2012). Joint genomic evaluation of French dairy cattle breeds using multiple-trait models. Genet. Sel. Evol., 44: 39.

Konkruea T., Koonaw ootrittriron S., Elzo M.A., Suwanasopee T. (2017). Genetic parameters and trends for daughters of imported and Thai Holstein sires for age at first calving and milk yield. Agric. Nat. Res., 51: 420-424.

K o on a w o trittriron S., Elzo M.A., Tumw a s orn S., Th ong prapi T. (2006). Age at first calving of dairy cattle in a multibreed population of Thailand. Proc. 44th Kasetsart University Annual Conference (Animals and Veterinary Medicine). Kasetsart University, Bangkok, Thailand.

K o on aw o otrittriron S., Elzo M.A., Thong prapi T. (2009). Genetic trends in a Holstein $\times$ other breeds multibreed dairy population in central Thailand. Livest. Sci., 122: 186-192.

L e garra A., A gu i la r I., M is zt a 1 I. (2009). A relationship matrix including full pedigree and genomic information. J. Dairy Sci., 92: 4656-4663.

M e u w is s e n T.H.E., H a y e s B.J., G o d d a r d M.E. (2001). Prediction of total genetic value using genome-wide dense marker maps. Genetics, 157: 1819-1829.

M e y e r K., H o u le D. (2013). Sampling based approximation of confidence intervals for functions of genetic covariance matrices. Proc. Assoc. Advmt. Anim. Breed. Genet., 20: 523-526.

Misztal I., Tsurut a S., Strabel T., A u vray B., Druet T., L e e D.H. (2002). BLUPF90 and related programs (BGF90). Proc. 7th World Congress on Genetic Applied to Livestock Production. Montpellier, France.

Moser G., Khatka r M.S., Haye s B.J., R a a d s ma H.W. (2010). Accuracy of direct genomic values in Holstein bulls and cows using subsets of SNP markers. Genet. Sel. Evol., 42: 37.

Mulder H.A., Calus M.P.L., Druet T., S chrooten C. (2012). Imputation of genotypes with low-density chips and its effect on reliability of direct genomic value in Dutch Holstein cattle. J. Dairy Sci., 95: 876-889.

Př i b y l J., B a u e r J., P e š e k P., Při b y l o vá J., Vo s trý L., Z a v a di 1 o vá L. (2014). Domestic and Interbull information in the single-step genomic evaluation of Holstein milk production. Czech J. Anim. Sci., 59: 409-415.

Rhone J.A., K o on aw o otrittriron S., Elzo M.A. (2008). Factors affecting milk yield, milk fat, bacterial score, and bulk tank somatic cell count of dairy farms in the central region of Thailand. Trop. Anim. Health Prod., 40: 147-153.

Rodríguez-R a mi lo S.T., García - Corté s L.A., Gonzále z-R e c i o Ó. (2014). Combining genomic and genealogical information in a reproducing kernel Hilbert spaces regression model for genome-enabled predictions in dairy cattle. PLoS ONE, 9: e93424. 
Sarakul M., Koonaw ootrittriron S., Elzo M.A., Suw a nas o pe e T. (2011). Factors influencing genetic change for milk yield within farm in Central Thailand. Asian-Aust. J. Anim. Sci., 24: $1031-1040$.

S a rg olza ei M., Ches na is J.P., S chenkel F.S. (2014). A new approach for efficient genotype imputation using information from relatives. BMC Genomics, 15: 478.

$\mathrm{S} \mathrm{ch}$ a e ffer L.R. (2006). Strategy for applying genome-wide selection in dairy cattle. J. Anim. Breed. Genet., 123: 218-223.

Schenkel F.S., Sargolzaei M., Kistemaker G., Jansen G.B., Sullivan P., Van D o orma a l B.J., Van Raden P.M., Wiggans G.R. (2009). Reliability of genomic evaluation of Holstein cattle in Canada. Proc. Interbull International Workshop, Uppsala, Sweden. pp. 51-58.

Su G., Mad s en P., Ni e ls e n U.S., Mänt y s a r i E.A., A a m a nd G.P., Chris t e n s en O.F., L und M.S. (2012). Genomic prediction for Nordic Red cattle using one-step and selection index blending. J. Dairy Sci., 95: 909-917.

Thai Meteorological Department (2010). The Thai Meteorological Department: Climate of Thailand. Available Source: http://www.tmd.go.th/info/climate_of_thailand-2524-2553.pdf, 18 July 2016.

Thom a s e n J.R., Gu ld brand t s en B., S u G., B røn d u m R.F., L und M.S. (2012). Reliabilities of genomic estimated breeding values in Danish Jersey. Animal, 6: 789-796.

T s u r u t a S. (2014). Average Information REML with several options including EM-REML and heterogeneous residual variances. Available Source: http://nce.ads.uga.edu/wiki/doku.php?id=application programs, 20 June 2016.

Van Doorma 1 B.J., K is te maker G.J., Sullivan P.G., S a rgolza e i M., S c he n kel F.S. (2009). Canadian implementation of genomic evaluations. Proc. Interbull International Workshop, Uppsala, Sweden. pp. 214-218.

Va n R a d e n P.M. (2008). Efficient methods to compute genomic predictions. J. Dairy Sci., 91: 44144423.

Van R a d e n P.M., Van Tas s e 11 C.P., Wiggan s G.R., S on s te gard T.S., S chnabel R.D., Ta y lor J.F., S c he n ke l F. (2009). Invited review: Reliability of genomic predictions for North American Holstein bulls. J. Dairy Sci., 92: 16-24.

Van Ra d e n P.M., O ' C on ne 11 J.R., Wiggan s G.R., We ig e 1 K.A. (2011). Genomic evaluations with many more genotypes. Genet. Sel. Evol., 43: 10.

Wiggan s G.R., Van R a d en P.M., C o o per T.A. (2011). The genomic evaluation system in the United States: past, present, future. J. Dairy Sci., 94: 3202-3211.

Ya e m k ong S., Ko on aw o otrittriron S., Elzo M.A., S u w a n a s o pe e T. (2010). Effect of experience, education, record keeping, labor and decision making on monthly milk yield and revenue of dairy farms supported by a private organization in Central Thailand. Asian-Aust. J. Anim. Sci., 23: 814-824.

Received: 16 IV 2018

Accepted: 26 IV 2019 